\title{
Strong Convergence Theorems of Modified Ishikawa Iterations for Countable Hemi-Relatively Nonexpansive Mappings in a Banach Space
}

\author{
Narin Petrot, ${ }^{1,2}$ Kriengsak Wattanawitoon, ${ }^{3,4}$ \\ and Poom Kumam ${ }^{2,3}$ \\ ${ }^{1}$ Department of Mathematics, Faculty of Science, Naresuan University, Phitsanulok 65000, Thailand \\ ${ }^{2}$ Centre of Excellence in Mathematics, CHE, Si Ayuthaya Road, Bangkok 10400, Thailand \\ ${ }^{3}$ Department of Mathematics, Faculty of Science, King Mongkut's University of Technology Thonburi \\ (KMUTT), Bangmod, Bangkok 10140, Thailand \\ ${ }^{4}$ Department of Mathematics and Statistics, Faculty of Science and Agricultural Technology, \\ Rajamangala University of Technology Lanna Tak, Tak 63000, Thailand
}

Correspondence should be addressed to Poom Kumam, poom.kum@kmutt.ac.th

Received 17 March 2009; Accepted 12 September 2009

Recommended by Lech Górniewicz

\begin{abstract}
We prove some strong convergence theorems for fixed points of modified Ishikawa and Halpern iterative processes for a countable family of hemi-relatively nonexpansive mappings in a uniformly convex and uniformly smooth Banach space by using the hybrid projection methods. Moreover, we also apply our results to a class of relatively nonexpansive mappings, and hence, we immediately obtain the results announced by Qin and Su's result (2007), Nilsrakoo and Saejung's result (2008), Su et al.'s result (2008), and some known corresponding results in the literatures.

Copyright (C) 2009 Narin Petrot et al. This is an open access article distributed under the Creative Commons Attribution License, which permits unrestricted use, distribution, and reproduction in any medium, provided the original work is properly cited.
\end{abstract}

\section{Introduction}

Let $C$ be a nonempty closed convex subset of a real Banach space $E$. A mapping $T: C \rightarrow C$ is said to be nonexpansive if $\|T x-T y\| \leq\|x-y\|$ for all $x, y \in C$. We denote by $F(T)$ the set of fixed points of $T$, that is $F(T)=\{x \in C: x=T x\}$. A mapping $T$ is said to be quasi-nonexpansive if $F(T) \neq \emptyset$ and $\|T x-y\| \leq\|x-y\|$ for all $x \in C$ and $y \in F(T)$. It is easy to see that if $T$ is nonexpansive with $F(T) \neq \emptyset$, then it is quasi-nonexpansive. Some iterative processes are often used to approximate a fixed point of a nonexpansive mapping. The Mann's iterative algorithm was introduced by Mann [1] in 1953. This iterative process is now known as Mann's iterative process, which is defined as

$$
x_{n+1}=\alpha_{n} x_{n}+\left(1-\alpha_{n}\right) T x_{n}, \quad n \geq 0,
$$


where the initial guess $x_{0}$ is taken in $C$ arbitrarily and the sequence $\left\{\alpha_{n}\right\}_{n=0}^{\infty}$ is in the interval $[0,1]$.

In 1976, Halpern [2] first introduced the following iterative scheme:

$$
\begin{gathered}
x_{0}=u \in C, \quad \text { chosen arbitrarily, } \\
x_{n+1}=\alpha_{n} u+\left(1-\alpha_{n}\right) T x_{n},
\end{gathered}
$$

see also Browder [3]. He pointed out that the conditions $\lim _{n \rightarrow \infty} \alpha_{n}=0$ and $\sum_{n=1}^{\infty} \alpha_{n}=\infty$ are necessary in the sence that, if the iteration (1.2) converges to a fixed point of $T$, then these conditions must be satisfied.

In 1974, Ishikawa [4] introduced a new iterative scheme, which is defined recursively by

$$
\begin{aligned}
y_{n} & =\beta_{n} x_{n}+\left(1-\beta_{n}\right) T x_{n}, \\
x_{n+1} & =\alpha_{n} x_{n}+\left(1-\alpha_{n}\right) T y_{n},
\end{aligned}
$$

where the initial guess $x_{0}$ is taken in $C$ arbitrarily and the sequences $\left\{\alpha_{n}\right\}$ and $\left\{\beta_{n}\right\}$ are in the interval $[0,1]$.

Concerning a family of nonexpansive mappings it has been considered by many authors. The well-known convex feasibility problem reduces to finding a point in the intersection of the fixed point sets of a family of nonexpansive mappings; see, for example, [5]. The problem of finding an optimal point that minimizes a given cost function over common set of fixed points of a family of nonexpansive mappings is of wide interdisciplinary interest and practical importance (see [6]).

Zhang and $\mathrm{Su}$ [7] introduced the following implicit hybrid method for a finite family of nonexpansive mappings $\left\{T_{i}\right\}_{i=1}^{N}$ in a real Hilbert space:

$$
\begin{aligned}
x_{0} & \in C \quad \text { is arbitrary, } \\
y_{n} & =\alpha_{n} x_{n}+\left(1-\alpha_{n}\right) T_{n} z_{n}, \\
z_{n} & =\beta_{n} y_{n}+\left(1-\beta_{n}\right) T_{n} y_{n}, \\
C_{n} & =\left\{z \in C:\left\|y_{n}-z\right\| \leq\left\|x_{n}-z\right\|\right\}, \\
Q_{n} & =\left\{z \in C:\left\langle x_{n}-z, x_{0}-x_{n}\right\rangle \geq 0\right\}, \\
x_{n+1} & =P_{C_{n} \cap Q_{n}}\left(x_{0}\right), \quad n=0,1,2, \ldots,
\end{aligned}
$$

where $T_{n} \equiv T_{n \bmod N},\left\{\alpha_{n}\right\}$ and $\left\{\beta_{n}\right\}$ are sequences in $[0,1]$ and $\left\{\alpha_{n}\right\} \subset[0, a]$ for some $a \in[0,1)$ and $\left\{\beta_{n}\right\} \subset[b, 1]$ for some $b \in(0,1]$.

In 2008, Nakprasit et al. [8] established weak and strong convergence theorems for finding common fixed points of a countable family of nonexpansive mappings in a real Hilbert space. In the same year, Cho et al. [9] introduced the normal Mann's iterative process and proved some strong convergence theorems for a finite family nonexpansive mapping in the framework Banach spaces. 
To find a common fixed point of a family of nonexpansive mappings, Aoyama et al. [10] introduced the following iterative sequence. Let $x_{1}=x \in C$ and

$$
x_{n+1}=\alpha_{n} x+\left(1-\alpha_{n}\right) T_{n} x_{n}
$$

for all $n \in \mathbb{N}$, where $C$ is a nonempty closed convex subset of a Banach space, $\left\{\alpha_{n}\right\}$ is a sequence of $[0,1]$, and $\left\{T_{n}\right\}$ is a sequence of nonexpansive mappings. Then they proved that, under some suitable conditions, the sequence $\left\{x_{n}\right\}$ defined by (1.5) converges strongly to a common fixed point of $\left\{T_{n}\right\}$.

In 2008, by using a (new) hybrid method, Takahashi et al. [11] proved the following theorem.

Theorem 1.1 (Takahashi et al. [11]). Let $H$ be a Hilbert space and let $C$ be a nonempty closed convex subset of $H$. Let $\left\{T_{n}\right\}$ and $T$ be families of nonexpansive mappings of $C$ into itself such that $\cap_{n=1}^{\infty} F\left(T_{n}\right):=F(\tau) \neq \emptyset$ and let $x_{0} \in H$. Suppose that $\left\{T_{n}\right\}$ satisfies the NST-condition $(I)$ with $\tau$. For $C_{1}=C$ and $x_{1}=P_{C_{1}} x_{0}$, define a sequence $\left\{x_{n}\right\}$ of $C$ as follows:

$$
\begin{aligned}
y_{n} & =\alpha_{n} x_{n}+\left(1-\alpha_{n}\right) T_{n} x_{n}, \\
C_{n+1} & =\left\{z \in C_{n}:\left\|y_{n}-z\right\| \leq\left\|x_{n}-z\right\|\right\}, \\
x_{n+1} & =P_{C_{n+1}} x_{0}, \quad n \in \mathbb{N},
\end{aligned}
$$

where $0 \leq \alpha_{n}<1$ for all $n \in \mathbb{N}$ and $\left\{T_{n}\right\}$ is said to satisfy the NST-condition (I) with $\tau$ if for each bounded sequence $\left\{z_{n}\right\} \subset C, \lim _{n \rightarrow \infty}\left\|z_{n}-T_{n} z_{n}\right\|=0$ implies that $\lim _{n \rightarrow \infty}\left\|z_{n}-T z_{n}\right\|=0$ for all $T \in \tau$. Then, $\left\{x_{n}\right\}$ converges strongly to $P_{F(\tau)} x_{0}$.

Note that, recently, many authors try to extend the above result from Hilbert spaces to a Banach space setting.

Let $E$ be a real Banach space with dual $E^{*}$. Denote by $\langle\cdot, \cdot\rangle$ the duality product. The normalized duality mapping $J$ from $E$ to $2^{E^{*}}$ is defined by $J x=\left\{f \in E^{*}:\langle x, f\rangle=\|x\|^{2}=\|f\|^{2}\right\}$, for all $x \in E$. The function $\phi: E \times E \rightarrow \mathbb{R}$ is defined by

$$
\phi(x, y)=\|x\|^{2}-2\langle x, J y\rangle+\|y\|^{2}, \quad \forall x, y \in E .
$$

A mapping $T$ is said to be hemi-relatively nonexpansive (see [12]) if $F(T) \neq \emptyset$ and

$$
\phi(p, T x) \leq \phi(p, x), \quad \forall x \in C, p \in F(T)
$$

A point $p$ in $C$ is said to be an asymptotic fixed point of $T$ [13] if $C$ contains a sequence $\left\{x_{n}\right\}$ which converges weakly to $p$ such that the strong $\lim _{n \rightarrow \infty}\left(x_{n}-T x_{n}\right)=0$. The set of asymptotic fixed points of $T$ will be denoted by $\widehat{F}(T)$. A hemi-relatively nonexpansive mapping $T$ from $C$ into itself is called relatively nonexpansive if $\widehat{F}(T)=F(T)$; see [14-16]) for more details. 
On the other hand, Matsushita and Takahashi [17] introduced the following iteration. A sequence $\left\{x_{n}\right\}$, defined by

$$
x_{n+1}=\Pi_{C} J^{-1}\left(\alpha_{n} J x_{n}+\left(1-\alpha_{n}\right) J T x_{n}\right), \quad n=0,1,2, \ldots,
$$

where the initial guess element $x_{0} \in C$ is arbitrary, $\left\{\alpha_{n}\right\}$ is a real sequence in [0,1], $T$ is a relatively nonexpansive mapping, and $\Pi_{C}$ denotes the generalized projection from $E$ onto a closed convex subset $C$ of $E$. Under some suitable conditions, they proved that the sequence $\left\{x_{n}\right\}$ converges weakly to a fixed point of $T$.

Recently, Kohsaka and Takahashi [18] extended iteration (1.9) to obtain a weak convergence theorem for common fixed points of a finite family of relatively nonexpansive mappings $\left\{T_{i}\right\}_{i=1}^{m}$ by the following iteration:

$$
x_{n+1}=\Pi_{C} J^{-1}\left(\sum_{i=1}^{m} w_{n, i}\left(\alpha_{n, i} J x_{n}+\left(1-\alpha_{n, i}\right) J T_{i} x_{n}\right)\right), \quad n=0,1,2, \ldots,
$$

where $\alpha_{n, i} \subset[0,1]$ and $w_{n, i} \subset[0,1]$ with $\sum_{i=1}^{m} w_{n, i}=1$, for all $n \in \mathbb{N}$. Moreover, Matsushita and Takahashi [14] proposed the following modification of iteration (1.9) in a Banach space $E$ :

$$
\begin{aligned}
x_{0} & =x \in C, \quad \text { chosen arbitrarily, } \\
y_{n} & =J^{-1}\left(\alpha_{n} J x_{n}+\left(1-\alpha_{n}\right) J T x_{n}\right), \\
C_{n} & =\left\{z \in C: \phi\left(z, y_{n}\right) \leq \phi\left(z, x_{n}\right)\right\}, \\
Q_{n} & =\left\{z \in C:\left\langle x_{n}-z, J x-J x_{n}\right\rangle \geq 0\right\}, \\
x_{n+1} & =\prod_{C_{n} \cap Q_{n}} x, \quad n=0,1,2, \ldots,
\end{aligned}
$$

and proved that the sequence $\left\{x_{n}\right\}$ converges strongly to $\Pi_{F(T)} x$.

Qin and $\mathrm{Su}[15]$ showed that the sequence $\left\{x_{n}\right\}$, which is generated by relatively nonexpansive mappings $T$ in a Banach space $E$, as follows:

$$
\begin{aligned}
x_{0} & \in C, \quad \text { chosen arbitrarily, } \\
y_{n} & =J^{-1}\left(\alpha_{n} J x_{n}+\left(1-\alpha_{n}\right) J T z_{n}\right), \\
z_{n} & =J^{-1}\left(\beta_{n} J x_{n}+\left(1-\beta_{n}\right) J T x_{n}\right), \\
C_{n} & =\left\{v \in C: \phi\left(v, y_{n}\right) \leq \alpha_{n} \phi\left(v, x_{n}\right)+\left(1-\alpha_{n}\right) \phi\left(v, z_{n}\right)\right\}, \\
Q_{n} & =\left\{v \in C:\left\langle J x_{0}-J x_{n}, x_{n}-v\right\rangle \geq 0\right\}, \\
x_{n+1} & =\prod_{C_{n} \cap Q_{n}} x_{0}
\end{aligned}
$$

converges strongly to $\Pi_{F(T)} x_{0}$. 
Fixed Point Theory and Applications

Moreover, they also showed that the sequence $\left\{x_{n}\right\}$, which is generated by

$$
\begin{aligned}
x_{0} & \in C, \quad \text { chosen arbitrarily, } \\
y_{n} & =J^{-1}\left(\alpha_{n} J x_{0}+\left(1-\alpha_{n}\right) J T x_{n}\right), \\
C_{n} & =\left\{v \in C: \phi\left(v, y_{n}\right) \leq \alpha_{n} \phi\left(v, x_{0}\right)+\left(1-\alpha_{n}\right) \phi\left(v, x_{n}\right)\right\}, \\
Q_{n} & =\left\{v \in C:\left\langle J x_{0}-J x_{n}, x_{n}-v\right\rangle \geq 0\right\}, \\
x_{n+1} & =\Pi_{C_{n} \cap Q_{n}} x_{0},
\end{aligned}
$$

converges strongly to $\Pi_{F(T)} x_{0}$.

In 2008, Nilsrakoo and Saejung [19] used the following Mann's iterative process:

$$
\begin{aligned}
x_{0} & \in C \quad \text { is arbitrary, } \\
C_{-1} & =Q_{-1}=C, \\
y_{n} & =J^{-1}\left(\alpha_{n} J x_{n}+\left(1-\alpha_{n}\right) J T_{n} x_{n}\right), \\
C_{n} & =\left\{v \in C_{n}: \phi\left(v, y_{n}\right) \leq \phi\left(v, x_{n}\right)\right\}, \\
Q_{n} & =\left\{v \in C:\left\langle J x_{0}-J x_{n}, x_{n}-v\right\rangle \geq 0\right\}, \\
x_{n+1} & =\Pi_{C_{n} \cap Q_{n}} x_{0}, \quad n=0,1,2, \ldots
\end{aligned}
$$

and showed that the sequence $\left\{x_{n}\right\}$ converges strongly to a common fixed point of a countable family of relatively nonexpansive mappings.

Recently, Su et al. [12] extended the results of Qin and Su [15], Matsushita and Takahashi [14] to a class of closed hemi-relatively nonexpansive mapping. Note that, since the hybrid iterative methods presented by Qin and Su [15] and Matsushita and Takahashi [14] cannot be used for hemi-relatively nonexpansive mappings. Thus, as we know, Su et al. [12] showed their results by using the method as a monotone (CQ) hybrid method.

In this paper, motivated by Qin and Su [15], Nilsrakoo and Saejung [19], we consider the modified Ishikawa iterative (1.12) and Halpern iterative processes (1.13), which is different from those of (1.12)-(1.14), for countable hemi-relatively nonexpansive mappings. By using the shrinking projection method, some strong convergence theorems in a uniformly convex and uniformly smooth Banach space are provided. Our results extend and improve the recent results by Nilsrakoo and Saejung's result [19], Qin and Su [15], Su et al. [12], Takahashi et al.'s theorem [11], and many others. 


\section{Preliminaries}

In this section, we will recall some basic concepts and useful well-known results.

A Banach space $E$ is said to be strictly convex if

$$
\left\|\frac{x+y}{2}\right\|<1
$$

for all $x, y \in E$ with $\|x\|=\|y\|=1$ and $x \neq y$. It is said to be uniformly convex if for any two sequences $\left\{x_{n}\right\}$ and $\left\{y_{n}\right\}$ in $E$ such that $\left\|x_{n}\right\|=\left\|y_{n}\right\|=1$ and

$$
\lim _{n \rightarrow \infty}\left\|x_{n}+y_{n}\right\|=2
$$

$\lim _{n \rightarrow \infty}\left\|x_{n}-y_{n}\right\|=0$ holds.

Let $U=\{x \in E:\|x\|=1\}$ be the unit sphere of $E$. Then the Banach space $E$ is said to be smooth if

$$
\lim _{t \rightarrow 0} \frac{\|x+t y\|-\|x\|}{t}
$$

exists for each $x, y \in U$. It is said to be uniformly smooth if the limit is attained uniformly for $x, y \in E$. In this case, the norm of $E$ is said to be Gâteaux differentiable. The space $E$ is said to have uniformly Gatteaux differentiable if for each $y \in U$, the limit (2.3) is attained uniformly for $y \in U$. The norm of $E$ is said to be uniformly Fréchet differentiable (and $E$ is said to be uniformly smooth) if the limit (2.3) is attained uniformly for $x, y \in U$.

In our work, the concept duality mapping is very important. Here, we list some known facts, related to the duality mapping $J$, as follows.

(a) $E\left(E^{*}\right.$, resp.) is uniformly convex if and only if $E^{*}(E$, resp.) is uniformly smooth.

(b) $J(x) \neq \emptyset$ for each $x \in E$.

(c) If $E$ is reflexive, then $J$ is a mapping of $E$ onto $E^{*}$.

(d) If $E$ is strictly convex, then $J(x) \cap J(y) \neq \emptyset$ for all $x \neq y$.

(e) If $E$ is smooth, then $J$ is single valued.

(f) If $E$ has a Fréchet differentiable norm, then $J$ is norm to norm continuous.

(g) If $E$ is uniformly smooth, then $J$ is uniformly norm to norm continuous on each bounded subset of $E$.

(h) If $E$ is a Hilbert space, then $J$ is the identity operator.

For more information, the readers may consult $[20,21]$.

If $C$ is a nonempty closed convex subset of a real Hilbert space $H$ and $P_{C}: H \rightarrow C$ is the metric projection, then $P_{C}$ is nonexpansive. Alber [22] has recently introduced a generalized projection operator $\Pi_{C}$ in a Banach space $E$ which is an analogue representation of the metric projection in Hilbert spaces. 
The generalized projection $\Pi_{C}: E \rightarrow C$ is a map that assigns to an arbitrary point $x \in E$ the minimum point of the functional $\phi(y, x)$, that is, $\Pi_{C} x=x^{*}$, where $x^{*}$ is the solution to the minimization problem

$$
\phi\left(x^{*}, x\right)=\min _{y \in C} \phi(y, x)
$$

Notice that the existence and uniqueness of the operator $\Pi_{C}$ is followed from the properties of the functional $\phi(y, x)$ and strict monotonicity of the mapping $J$, and moreover, in the Hilbert spaces setting we have $\Pi_{C}=P_{C}$. It is obvious from the definition of the function $\phi$ that

$$
(\|y\|-\|x\|)^{2} \leq \phi(y, x) \leq(\|y\|+\|x\|)^{2}, \quad \forall x, y \in E .
$$

Remark 2.1. If $E$ is a strictly convex and a smooth Banach space, then for all $x, y \in E, \phi(y, x)=$ 0 if and only if $x=y$, see Matsushita and Takahashi [14].

To obtain our results, following lemmas are important.

Lemma 2.2 (Kamimura and Takahashi [23]). Let E be a uniformly convex and smooth Banach space and let $r>0$. Then there exists a continuous strictly increasing and convex function $g$ : $[0,2 r] \rightarrow[0, \infty)$ such that $g(0)=0$ and

$$
g(\|x-y\|) \leq \phi(x, y)
$$

for all $x, y \in B_{r}=\{z \in E:\|z\| \leq r\}$.

Lemma 2.3 (Kamimura and Takahashi [23]). Let E be a uniformly convex and smooth real Banach space and let $\left\{x_{n}\right\},\left\{y_{n}\right\}$ be two sequences of $E$. If $\phi\left(x_{n}, y_{n}\right) \rightarrow 0$ and either $\left\{x_{n}\right\}$ or $\left\{y_{n}\right\}$ is bounded, then $\left\|x_{n}-y_{n}\right\| \rightarrow 0$.

Lemma 2.4 (Alber [22]). Let $C$ be a nonempty closed convex subset of a smooth real Banach space $E$ and $x \in E$. Then, $x_{0}=\Pi_{C} x$ if and only if

$$
\left\langle x_{0}-y, J x-J x_{0}\right\rangle \geq 0, \quad \forall y \in C
$$

Lemma 2.5 (Alber [22]). Let $E$ be a reflexive strict convex and smooth real Banach space, let $C$ be a nonempty closed convex subset of $E$ and let $x \in E$. Then

$$
\phi\left(y, \Pi_{C} x\right)+\phi\left(\Pi_{C} x, x\right) \leq \phi(y, x), \quad \forall y \in C .
$$

Lemma 2.6 (Matsushita and Takahashi [14]). Let E be a strictly convex and smooth real Banach space, let $C$ be a closed convex subset of $E$, and let $T$ be a hemi-relatively nonexpansive mapping from $C$ into itself. Then $F(T)$ is closed and convex. 
Let $C$ be a subset of a Banach space $E$ and let $\left\{T_{n}\right\}$ be a family of mappings from $C$ into $E$. For a subset $B$ of $C$, one says that

(a) $\left(\left\{T_{n}\right\}, B\right)$ satisfies condition AKTT if

$$
\sum_{n=1}^{\infty} \sup \left\{\left\|T_{n+1} z-T_{n} z\right\|: z \in B\right\}<\infty
$$

(b) $\left(\left\{T_{n}\right\}, B\right)$ satisfies condition ${ }^{*}$ AKTT if

$$
\sum_{n=1}^{\infty} \sup \left\{\left\|J T_{n+1} z-J T_{n} z\right\|: z \in B\right\}<\infty
$$

For more information, see Aoyama et al. [10].

Lemma 2.7 (Aoyama et al. [10]). Let $C$ be a nonempty subset of a Banach space $E$ and let $\left\{T_{n}\right\}$ be a sequence of mappings from $C$ into $E$. Let $B$ be a subset of $C$ with $\left(\left\{T_{n}\right\}, B\right)$ satisfying condition AKTT, then there exists a mapping $\tilde{T}: B \rightarrow E$ such that

$$
\tilde{T} x=\lim _{n \rightarrow \infty} T_{n} x, \quad \forall x \in B
$$

and $\lim \sup _{n \rightarrow \infty}\left\{\left\|\tilde{T} z-T_{n} z\right\|: z \in B\right\}=0$.

Inspired by Lemma 2.7, Nilsrakoo and Saejung [19] prove the following results.

Lemma 2.8 (Nilsrakoo and Saejung [19]). Let E be a reflexive and strictly convex Banach space whose norm is Fréchet differentiable, let $C$ be a nonempty subset of a Banach space $E$, and let $\left\{T_{n}\right\}$ be a sequence of mappings from $C$ into $E$. Let $B$ be a subset of $C$ with $\left(\left\{T_{n}\right\}, B\right)$ satisfies condition *AKTT, then there exists a mapping $\widehat{T}: B \rightarrow$ E such that

$$
\widehat{T} x=\lim _{n \rightarrow \infty} T_{n} x, \quad \forall x \in B
$$

and $\lim \sup _{n \rightarrow \infty}\left\{\left\|J \widehat{T} z-J T_{n} z\right\|: z \in B\right\}=0$.

Lemma 2.9 (Nilsrakoo and Saejung [19]). Let E be a reflexive and strictly convex Banach space whose norm is Fréchet differentiable, let $C$ be a nonempty subset of a Banach space $E$, and let $\left\{T_{n}\right\}$ be a sequence of mappings from $C$ into $E$. Suppose that for each bounded subset $B$ of $C$, the ordered pair $\left(\left\{T_{n}\right\}, B\right)$ satisfies either condition AKTT or condition *AKTT. Then there exists a mapping $T: B \rightarrow$ E such that

$$
T x=\lim _{n \rightarrow \infty} T_{n} x, \quad \forall x \in C .
$$




\section{Modified Ishikawa Iterative Scheme}

In this section, we establish the strong convergence theorems for finding common fixed points of a countable family of hemi-relatively nonexpansive mappings in a uniformly convex and uniformly smooth Banach space. It is worth mentioning that our main theorem generalizes recent theorems by $\mathrm{Su}$ et al. [12] from relatively nonexpansive mappings to a more general concept. Moreover, our results also improve and extend the corresponding results of Nilsrakoo and Saejung [19]. In order to prove the main result, we recall a concept as follows. An operator $T$ in a Banach space is closed if $x_{n} \rightarrow x$ and $T x_{n} \rightarrow y$, then $T x=y$.

Theorem 3.1. Let $E$ be a uniformly convex and uniformly smooth Banach space and let $C$ be a nonempty bounded closed convex subset of $E$. Let $\left\{T_{n}\right\}$ be a sequence of hemi-relatively nonexpansive mappings from $C$ into itself such that $\bigcap_{n=0}^{\infty} F\left(T_{n}\right)$ is nonempty. Assume that $\left\{a_{n}\right\}_{n=0}^{\infty}$ and $\left\{\beta_{n}\right\}_{n=0}^{\infty}$ are sequences in $[0,1]$ such that $\limsup _{n \rightarrow \infty} \alpha_{n}<1$ and $\lim _{n \rightarrow \infty} \beta_{n}=1$ and let a sequence $\left\{x_{n}\right\}$ in $C$ by the following algorithm be:

$$
\begin{aligned}
x_{0} & \in C, \quad \text { chosen arbitrarity, } \quad C_{0}=C, \\
y_{n} & =J^{-1}\left(\alpha_{n} J x_{n}+\left(1-\alpha_{n}\right) J T_{n} z_{n}\right), \\
z_{n} & =J^{-1}\left(\beta_{n} J x_{n}+\left(1-\beta_{n}\right) J T_{n} x_{n}\right), \\
C_{n+1} & =\left\{v \in C_{n}: \phi\left(v, y_{n}\right) \leq \phi\left(v, x_{n}\right)\right\}, \\
x_{n+1} & =\prod_{C_{n+1}} x_{0},
\end{aligned}
$$

for $n \in \mathbb{N} \cup\{0\}$, where $J$ is the single-valued duality mapping on E. Suppose that for each bounded subset $B$ of $C$, the ordered pair $\left(\left\{T_{n}\right\}, B\right)$ satisfies either condition AKTT or condition ${ }^{*} A K T T$. Let $T$ be the mapping from $C$ into itself defined by $T v=\lim _{n \rightarrow \infty} T_{n} v$ for all $v \in C$ and suppose that $T$ is closed and $F(T)=\bigcap_{n=0}^{\infty} F\left(T_{n}\right)$. If $T_{n}$ is uniformly continuous for all $n \in \mathbb{N}$, then $\left\{x_{n}\right\}$ converges strongly to $\Pi_{F(T)} x_{0}$, where $\Pi_{F(T)}$ is the generalized projection from $C$ onto $F(T)$.

Proof. We first show that $C_{n+1}$ is closed and convex for each $n \geq 0$. Obviously, from the definition of $C_{n+1}$, we see that $C_{n+1}$ is closed for each $n \geq 0$. Now we show that $C_{n+1}$ is convex for any $n \geq 0$. Since

$$
\phi\left(v, y_{n}\right) \leq \phi\left(v, x_{n}\right) \Longleftrightarrow 2\left\langle v, J x_{n}-J y_{n}\right\rangle+\left\|y_{n}\right\|^{2}-\left\|x_{n}\right\|^{2} \leq 0
$$

this implies that $C_{n+1}$ is a convex set. Next, we show that $\bigcap_{n=0}^{\infty} F\left(T_{n}\right) \subset C_{n}$ for all $n \geq 0$. Indeed, 
let $p \in \bigcap_{n=0}^{\infty} F\left(T_{n}\right)$, we have

$$
\begin{aligned}
\phi\left(p, y_{n}\right) & =\phi\left(p, J^{-1}\left(\alpha_{n} J x_{n}+\left(1-\alpha_{n}\right) J T_{n} z_{n}\right)\right) \\
& =\|p\|^{2}-2\left\langle p, \alpha_{n} J x_{n}+\left(1-\alpha_{n}\right) J T_{n} z_{n}\right\rangle+\left\|\alpha_{n} J x_{n}+\left(1-\alpha_{n}\right) J T_{n} z_{n}\right\|^{2} \\
& \leq\|p\|^{2}-2 \alpha_{n}\left\langle p, J x_{n}\right\rangle-2\left(1-\alpha_{n}\right)\left\langle p, J T_{n} z_{n}\right\rangle+\alpha_{n}\left\|x_{n}\right\|^{2}+\left(1-\alpha_{n}\right)\left\|T_{n} z_{n}\right\|^{2} \\
& =\alpha_{n}\left(\|p\|^{2}-2\left\langle p, J x_{n}\right\rangle+\left\|x_{n}\right\|^{2}\right)+\left(1-\alpha_{n}\right)\left(\|p\|^{2}-2\left\langle p, J T_{n} z_{n}\right\rangle+\left\|T_{n} z_{n}\right\|^{2}\right) \\
& \leq \alpha_{n} \phi\left(p, x_{n}\right)+\left(1-\alpha_{n}\right) \phi\left(p, T_{n} z_{n}\right) \\
& \leq \alpha_{n} \phi\left(p, x_{n}\right)+\left(1-\alpha_{n}\right) \phi\left(p, z_{n}\right), \\
\phi\left(p, z_{n}\right) & =\phi\left(p, J^{-1}\left(\beta_{n} J x_{n}+\left(1-\beta_{n}\right) J T_{n} x_{n}\right)\right) \\
& =\|p\|^{2}-2\left\langle p, \beta_{n} J x_{n}+\left(1-\beta_{n}\right) J T_{n} x_{n}\right\rangle+\left\|\beta_{n} J x_{n}+\left(1-\beta_{n}\right) J T_{n} x_{n}\right\|^{2} \\
& =\|p\|^{2}-2 \beta_{n}\left\langle p, J x_{n}\right\rangle-2\left(1-\beta_{n}\right)\left\langle p, J T_{n} x_{n}\right\rangle+\beta_{n}\left\|x_{n}\right\|^{2}+\left(1-\beta_{n}\right)\left\|T_{n} x_{n}\right\|^{2} \\
& =\beta_{n}\left(\|p\|^{2}-2\left\langle p, J x_{n}\right\rangle+\left\|x_{n}\right\|^{2}\right)+\left(1-\beta_{n}\right)\left(\|p\|^{2}-2\left\langle p, J T_{n} x_{n}\right\rangle+\left\|T_{n} x_{n}\right\|^{2}\right) \\
& \leq \beta_{n} \phi\left(p, x_{n}\right)+\left(1-\beta_{n}\right) \phi\left(p, T_{n} x_{n}\right) \\
& \leq \beta_{n} \phi\left(p, x_{n}\right)+\left(1-\beta_{n}\right) \phi\left(p, x_{n}\right) \\
& \leq \phi\left(p, x_{n}\right) .
\end{aligned}
$$

Substituting (3.4) into (3.3), we have

$$
\phi\left(p, y_{n}\right) \leq \phi\left(p, x_{n}\right)
$$

This means that, $p \in C_{n+1}$ for all $n \geq 0$. Consequently, the sequence $\left\{x_{n}\right\}$ is well defined. Moreover, since $x_{n}=\Pi_{C_{n}} x_{0}$ and $x_{n+1} \in C_{n+1} \subset C_{n}$, we get

$$
\phi\left(x_{n}, x_{0}\right) \leq \phi\left(x_{n+1}, x_{0}\right)
$$

for all $n \geq 0$. Therefore, $\left\{\phi\left(x_{n}, x_{0}\right)\right\}$ is nondecreasing.

By the definition of $x_{n}$ and Lemma 2.5, we have

$$
\phi\left(x_{n}, x_{0}\right)=\phi\left(\Pi_{C_{n}} x_{0}, x_{0}\right) \leq \phi\left(p, x_{0}\right)-\phi\left(p, \Pi_{C_{n}} x_{0}\right) \leq \phi\left(p, x_{0}\right),
$$


for all $p \in \bigcap_{n=0}^{\infty} F\left(T_{n}\right) \subset C_{n}$. Thus, $\left\{\phi\left(x_{n}, x_{0}\right)\right\}$ is a bounded sequence. Moreover, by (2.5), we know that $\left\{x_{n}\right\}$ is bounded. So, $\lim _{n \rightarrow \infty} \phi\left(x_{n}, x_{0}\right)$ exists. Again, by Lemma 2.5, we have

$$
\begin{aligned}
\phi\left(x_{n+1}, x_{n}\right) & =\phi\left(x_{n+1}, \Pi_{C_{n}} x_{0}\right) \\
& \leq \phi\left(x_{n+1}, x_{0}\right)-\phi\left(\Pi_{C_{n}} x_{0}, x_{0}\right) \\
& =\phi\left(x_{n+1}, x_{0}\right)-\phi\left(x_{n}, x_{0}\right),
\end{aligned}
$$

for all $n \geq 0$. Thus, $\phi\left(x_{n+1}, x_{n}\right) \rightarrow 0$ as $n \rightarrow \infty$.

Next, we show that $\left\{x_{n}\right\}$ is a Cauchy sequence. Using Lemma 2.2, for $m, n$ such that $m>n$, we have

$$
g\left(\left\|x_{m}-x_{n}\right\|\right) \leq \phi\left(x_{m}, x_{n}\right) \leq \phi\left(x_{m}, x_{0}\right)-\phi\left(x_{n}, x_{0}\right),
$$

where $g:[0, \infty) \rightarrow[0, \infty)$ is a continuous stricly increasing and convex function with $g(0)=$ 0 . Then the properties of the function $g$ yield that $\left\{x_{n}\right\}$ is a Cauchy sequence. Thus, we can say that $\left\{x_{n}\right\}$ converges strongly to $p$ for some point $p$ in $C$. However, since $\lim _{n \rightarrow \infty} \beta_{n}=1$ and $\left\{x_{n}\right\}$ is bounded, we obtain

$$
\begin{aligned}
\phi\left(x_{n+1}, z_{n}\right) & =\phi\left(x_{n+1}, J^{-1}\left(\beta_{n} J x_{n}+\left(1-\beta_{n}\right) J T_{n} x_{n}\right)\right) \\
& =\left\|x_{n+1}\right\|^{2}-2\left\langle x_{n+1}, \beta_{n} J x_{n}+\left(1-\beta_{n}\right) J T_{n} x_{n}\right\rangle+\left\|\beta_{n} J x_{n}+\left(1-\beta_{n}\right) J T_{n} x_{n}\right\|^{2} \\
& \leq\left\|x_{n+1}\right\|^{2}-2 \beta_{n}\left\langle x_{n+1}, J x_{n}\right\rangle-2\left(1-\beta_{n}\right)\left\langle x_{n+1}, J T_{n} x_{n}\right\rangle+\beta_{n}\left\|x_{n}\right\|^{2}+\left(1-\beta_{n}\right)\left\|T_{n} x_{n}\right\|^{2} \\
& =\beta_{n} \phi\left(x_{n+1}, x_{n}\right)+\left(1-\beta_{n}\right) \phi\left(x_{n+1}, T_{n} x_{n}\right) .
\end{aligned}
$$

Therefore $\phi\left(x_{n+1}, z_{n}\right) \rightarrow 0$ as $n \rightarrow \infty$.

Since $x_{n+1}=\Pi_{C_{n+1}} x_{0} \in C_{n+1}$, from the definition of $C_{n}$, we have

$$
\phi\left(x_{n+1}, y_{n}\right) \leq \phi\left(x_{n+1}, x_{n}\right)
$$

for all $n \geq 0$. Thus

$$
\phi\left(x_{n+1}, y_{n}\right) \longrightarrow 0, \quad \text { as } n \longrightarrow \infty
$$

By using Lemma 2.3, we also have

$$
\lim _{n \rightarrow \infty}\left\|x_{n+1}-y_{n}\right\|=\lim _{n \rightarrow \infty}\left\|x_{n+1}-x_{n}\right\|=\lim _{n \rightarrow \infty}\left\|x_{n+1}-z_{n}\right\|=0
$$

Since $J$ is uniformly norm-to-norm continuous on bounded sets, we have

$$
\lim _{n \rightarrow \infty}\left\|J x_{n+1}-J y_{n}\right\|=\lim _{n \rightarrow \infty}\left\|J x_{n+1}-J x_{n}\right\|=\lim _{n \rightarrow \infty}\left\|J x_{n+1}-J z_{n}\right\|=0
$$


For each $n \in \mathbb{N} \cup\{0\}$, we observe that

$$
\begin{aligned}
\left\|J x_{n+1}-J y_{n}\right\| & =\left\|J x_{n+1}-\left(\alpha_{n} J x_{n}+\left(1-\alpha_{n}\right) J T_{n} z_{n}\right)\right\| \\
& =\left\|\alpha_{n}\left(J x_{n+1}-J x_{n}\right)+\left(1-\alpha_{n}\right)\left(J x_{n+1}-J T_{n} z_{n}\right)\right\| \\
& =\left\|\left(1-\alpha_{n}\right)\left(J x_{n+1}-J T_{n} z_{n}\right)-\alpha_{n}\left(J x_{n}-J x_{n+1}\right)\right\| \\
& \geq\left(1-\alpha_{n}\right)\left\|J x_{n+1}-J T_{n} z_{n}\right\|-\alpha_{n}\left\|J x_{n}-J x_{n+1}\right\| .
\end{aligned}
$$

It follows that

$$
\left\|J x_{n+1}-J T_{n} z_{n}\right\| \leq \frac{1}{1-\alpha_{n}}\left(\left\|J x_{n+1}-J y_{n}\right\|+\alpha_{n}\left\|J x_{n}-J x_{n+1}\right\|\right) .
$$

By (3.14) and limsup $\sup _{n \rightarrow \infty} \alpha_{n}<1$, we obtain

$$
\lim _{n \rightarrow \infty}\left\|J x_{n+1}-J T_{n} z_{n}\right\|=0
$$

Since $J^{-1}$ is uniformly norm-to-norm continuous on bounded sets, we have

$$
\lim _{n \rightarrow \infty}\left\|x_{n+1}-T_{n} z_{n}\right\|=0
$$

By (3.13), we have

$$
\left\|z_{n}-x_{n}\right\| \leq\left\|z_{n}-x_{n+1}\right\|+\left\|x_{n+1}-x_{n}\right\| \longrightarrow 0, \quad \text { as } n \longrightarrow \infty
$$

Since $T_{n}$ is uniformly continuous, by (3.13) and (3.18), we obtain

$$
\left\|x_{n}-T_{n} x_{n}\right\| \leq\left\|x_{n}-x_{n+1}\right\|+\left\|x_{n+1}-T_{n} z_{n}\right\|+\left\|T_{n} z_{n}-T_{n} x_{n}\right\| \longrightarrow 0,
$$

as $n \rightarrow \infty$, and so

$$
\lim _{n \rightarrow \infty}\left\|J x_{n}-J T_{n} x_{n}\right\|=0
$$

Based on the hypothesis, we now consider the following two cases.

Case 1. $\left(\left\{T_{n}\right\},\left\{x_{n}\right\}\right)$ satisfies condition *AKTT. Applying Lemma 2.8 to get

$$
\begin{aligned}
\left\|J x_{n}-J T x_{n}\right\| & \leq\left\|J x_{n}-J T_{n} x_{n}\right\|+\left\|J T_{n} x_{n}-J T x_{n}\right\| \\
& \leq\left\|J x_{n}-J T_{n} x_{n}\right\|+\sup \left\{\left\|J T_{n} z-J T z\right\|: z \in\left\{x_{n}\right\}\right\} \longrightarrow 0 .
\end{aligned}
$$


Fixed Point Theory and Applications

Case 2. $\left(\left\{T_{n}\right\},\left\{x_{n}\right\}\right)$ satisfies condition AKTT. Apply Lemma 2.7 to get

$$
\begin{aligned}
\left\|x_{n}-T x_{n}\right\| & \leq\left\|x_{n}-T_{n} x_{n}\right\|+\left\|T_{n} x_{n}-T x_{n}\right\| \\
& \leq\left\|x_{n}-T_{n} x_{n}\right\|+\sup \left\{\left\|T_{n} z-T z\right\|: z \in\left\{x_{n}\right\}\right\} \longrightarrow 0 .
\end{aligned}
$$

Hence

$$
\lim _{n \rightarrow \infty}\left\|x_{n}-T x_{n}\right\|=\lim _{n \rightarrow \infty}\left\|J^{-1}\left(J x_{n}\right)-J^{-1}\left(J T x_{n}\right)\right\|=0 .
$$

Therefore, from the both two cases, we have

$$
\lim _{n \rightarrow \infty}\left\|x_{n}-T x_{n}\right\|=0
$$

Since $T$ is closed and $x_{n} \rightarrow p$, we have $p \in F(T)$. Moreover, by (3.7), we obtain

$$
\phi\left(p, x_{0}\right)=\lim _{n \rightarrow \infty} \phi\left(x_{n}, x_{0}\right) \leq \phi\left(p, x_{0}\right)
$$

for all $p \in F(T)$. Therefore, $p=\Pi_{F(T)} x_{0}$. This completes the proof.

Since every relatively nonexpansive mapping is a hemi-relatively nonexpansive mapping, we obtain the following result for a countable family of relatively nonexpansive mappings of modified Ishikawa iterative process.

Corollary 3.2. Let $E$ be a uniformly convex and uniformly smooth Banach space and let $C$ be a nonempty bounded closed convex subset of $E$. Let $\left\{T_{n}\right\}$ be a sequence of relatively nonexpansive mappings from $C$ into itself such that $\bigcap_{n=0}^{\infty} F\left(T_{n}\right)$ is nonempty. Assume that $\left\{\alpha_{n}\right\}_{n=0}^{\infty}$ and $\left\{\beta_{n}\right\}_{n=0}^{\infty}$ are sequences in $[0,1]$ such that $\limsup _{n \rightarrow \infty} \alpha_{n}<1$ and $\lim _{n \rightarrow \infty} \beta_{n}=1$ and let a sequence $\left\{x_{n}\right\}$ in $C$ be defined by the following algorithm:

$$
\begin{aligned}
x_{0} & \in C, \quad \text { chosen arbitrarity, } \quad C_{0}=C, \\
y_{n} & =J^{-1}\left(\alpha_{n} J x_{n}+\left(1-\alpha_{n}\right) J T_{n} z_{n}\right), \\
z_{n} & =J^{-1}\left(\beta_{n} J x_{n}+\left(1-\beta_{n}\right) J T_{n} x_{n}\right), \\
C_{n+1} & =\left\{v \in C_{n}: \phi\left(v, y_{n}\right) \leq \phi\left(v, x_{n}\right)\right\}, \\
x_{n+1} & =\Pi_{C_{n+1}} x_{0},
\end{aligned}
$$

for $n \in \mathbb{N} \cup\{0\}$, where $J$ is the single-valued duality mapping on $E$. Suppose that for each bounded subset $B$ of $C$, the ordered pair $\left(\left\{T_{n}\right\}, B\right)$ satisfies either condition AKTT or condition *AKTT. Let $T$ be the mapping from $C$ into itself defined by $T v=\lim _{n \rightarrow \infty} T_{n} v$ for all $v \in C$ and suppose that $T$ is closed and $F(T)=\bigcap_{n=0}^{\infty} F\left(T_{n}\right)$. If $T_{n}$ is uniformly continuous for all $n \in \mathbb{N}$, then $\left\{x_{n}\right\}$ converges strongly to $\Pi_{F(T)} x_{0}$, where $\Pi_{F(T)}$ is the generalized projection from $C$ onto $F(T)$. 
Theorem 3.3. Let $E$ be a uniformly convex and uniformly smooth Banach space and let $C$ be a nonempty bounded closed convex subset of $E$. Let $\left\{T_{n}\right\}$ be a sequence of hemi-relatively nonexpansive mappings from $C$ into itself such that $\bigcap_{n=0}^{\infty} F\left(T_{n}\right)$ is nonempty. Assume that $\left\{\alpha_{n}\right\}_{n=0}^{\infty}$ is a sequence in $[0,1]$ such that $\lim _{\sup _{n \rightarrow \infty}} \alpha_{n}<1$ and let a sequence $\left\{x_{n}\right\}$ in $C$ be defined by the following algorithm:

$$
\begin{aligned}
x_{0} & \in C, \quad \text { chosen arbitrarity, } \quad C_{0}=C, \\
y_{n} & =J^{-1}\left(\alpha_{n} J x_{n}+\left(1-\alpha_{n}\right) J T_{n} x_{n}\right), \\
C_{n+1} & =\left\{v \in C_{n}: \phi\left(v, y_{n}\right) \leq \phi\left(v, x_{n}\right)\right\}, \\
x_{n+1} & =\prod_{C_{n+1}} x_{0},
\end{aligned}
$$

for $n \in \mathbb{N} \cup\{0\}$, where $J$ is the single-valued duality mapping on E. Suppose that for each bounded subset $B$ of $C$, the ordered pair $\left(\left\{T_{n}\right\}, B\right)$ satisfies either condition AKTT or condition *AKTT. Let $T$ be the mapping from $C$ into itself defined by $T v=\lim _{n \rightarrow \infty} T_{n} v$ for all $v \in C$ and suppose that $T$ is closed and $F(T)=\bigcap_{n=0}^{\infty} F\left(T_{n}\right)$. Then $\left\{x_{n}\right\}$ converges strongly to $\prod_{F(T)} x_{0}$.

Proof. In Theorem 3.1, if $\beta_{n}=1$ for all $n \in \mathbb{N} \cup\{0\}$ then (3.1) reduced to (3.28).

Corollary 3.4. Let $E$ be a uniformly convex and uniformly smooth Banach space and let $C$ be a nonempty bounded closed convex subset of $E$. Let $\left\{T_{n}\right\}$ be a sequence of relatively nonexpansive mappings from $C$ into itself such that $\bigcap_{n=0}^{\infty} F\left(T_{n}\right)$ is nonempty. Assume that $\left\{\alpha_{n}\right\}_{n=0}^{\infty}$ is a sequence in $[0,1]$ such that $\limsup _{n \rightarrow \infty} \alpha_{n}<1$ and let a sequence $\left\{x_{n}\right\}$ in $C$ be defined by the following algorithm:

$$
\begin{aligned}
x_{0} & \in C, \quad \text { chosen arbitrarity, } \quad C_{0}=C, \\
y_{n} & =J^{-1}\left(\alpha_{n} J x_{n}+\left(1-\alpha_{n}\right) J T_{n} x_{n}\right), \\
C_{n+1} & =\left\{v \in C_{n}: \phi\left(v, y_{n}\right) \leq \phi\left(v, x_{n}\right)\right\}, \\
x_{n+1} & =\prod_{C_{n+1}} x_{0},
\end{aligned}
$$

for $n \in \mathbb{N} \cup\{0\}$, where $J$ is the single-valued duality mapping on E. Suppose that for each bounded subset $B$ of $C$, the ordered pair $\left(\left\{T_{n}\right\}, B\right)$ satisfies either condition AKTT or condition * AKTT. Let $T$ be the mapping from $C$ into itself defined by $T v=\lim _{n \rightarrow \infty} T_{n} v$ for all $v \in C$ and suppose that $T$ is closed and $F(T)=\bigcap_{n=0}^{\infty} F\left(T_{n}\right)$. Then $\left\{x_{n}\right\}$ converges strongly to $\Pi_{F(T)} x_{0}$.

Notice that every uniformly continuous mapping must be a continuous and closed mapping. Then setting $T_{n} \equiv T$ for all $n \in \mathbb{N}$, in Theorems 3.1 and 3.3, we immediately obtain the following results.

Corollary 3.5. Let $E$ be a uniformly convex and uniformly smooth Banach space and let $C$ be a nonempty bounded closed convex subset of $E$. Let $T: C \rightarrow C$ be a closed hemi-relatively nonexpansive mapping such that $F(T) \neq \emptyset$. Assume that $\left\{\alpha_{n}\right\}_{n=0}^{\infty}$ and $\left\{\beta_{n}\right\}_{n=0}^{\infty}$ are sequences in $[0,1]$ such that 
$\limsup _{n \rightarrow \infty} \alpha_{n}<1$ and $\lim _{n \rightarrow \infty} \beta_{n}=1$ and let a sequence $\left\{x_{n}\right\}$ in $C$ be defined by the following algorithm:

$$
\begin{aligned}
x_{0} & \in C, \quad \text { chosen arbitrarity, } \quad C_{0}=C, \\
y_{n} & =J^{-1}\left(\alpha_{n} J x_{n}+\left(1-\alpha_{n}\right) J T z_{n}\right), \\
z_{n} & =J^{-1}\left(\beta_{n} J x_{n}+\left(1-\beta_{n}\right) J T x_{n}\right), \\
C_{n+1} & =\left\{v \in C_{n}: \phi\left(v, y_{n}\right) \leq \phi\left(v, x_{n}\right)\right\}, \\
x_{n+1} & =\prod_{C_{n+1}} x_{0},
\end{aligned}
$$

for $n \in \mathbb{N} \cup\{0\}$, where $J$ is the single-valued duality mapping on E. If $T$ is uniformly continuous, then $\left\{x_{n}\right\}$ converges strongly to $\Pi_{F(T)} x_{0}$.

Corollary 3.6. Let $E$ be a uniformly convex and uniformly smooth Banach space and let $C$ be a nonempty bounded closed convex subset of $E$. Let $T: C \rightarrow C$ be a closed relatively nonexpansive mapping such that $F(T) \neq \emptyset$. Assume that $\left\{\alpha_{n}\right\}_{n=0}^{\infty}$ and $\left\{\beta_{n}\right\}_{n=0}^{\infty}$ are sequences in $[0,1]$ such that $\limsup _{n \rightarrow \infty} \alpha_{n}<1$ and $\lim _{n \rightarrow \infty} \beta_{n}=1$ and let a sequence $\left\{x_{n}\right\}$ in $C$ be defined by the following algorithm:

$$
\begin{aligned}
x_{0} & \in C, \quad \text { chosen arbitrarity, } \quad C_{0}=C, \\
y_{n} & =J^{-1}\left(\alpha_{n} J x_{n}+\left(1-\alpha_{n}\right) J T z_{n}\right), \\
z_{n} & =J^{-1}\left(\beta_{n} J x_{n}+\left(1-\beta_{n}\right) J T x_{n}\right), \\
C_{n+1} & =\left\{v \in C_{n}: \phi\left(v, y_{n}\right) \leq \phi\left(v, x_{n}\right)\right\}, \\
x_{n+1} & =\prod_{C_{n+1}} x_{0},
\end{aligned}
$$

for $n \in \mathbb{N} \cup\{0\}$, where $J$ is the single-valued duality mapping on E. If $T$ is uniformly continuous, then $\left\{x_{n}\right\}$ converges strongly to $\Pi_{F(T)} x_{0}$.

Proof. Since a closed relatively nonexpansive mapping is a closed hemi-relatively one, Corollary 3.6 is implied by Corollary 3.5.

Corollary 3.7. Let $E$ be a uniformly convex and uniformly smooth Banach space and let $C$ be a nonempty bounded closed convex subset of $E$. Let $T: C \rightarrow C$ be a closed hemi-relatively nonexpansive mapping from $C$ into itself such that $F(T) \neq \emptyset$. Assume that $\left\{\alpha_{n}\right\}_{n=0}^{\infty}$ is a sequence in $[0,1]$ such that $\limsup _{n \rightarrow \infty} \alpha_{n}<1$ and let a sequence $\left\{x_{n}\right\}$ in $C$ be defined by the following algorithm:

$$
\begin{aligned}
x_{0} & \in C, \quad \text { chosen arbitrarity, } \quad C_{0}=C, \\
y_{n} & =J^{-1}\left(\alpha_{n} J x_{n}+\left(1-\alpha_{n}\right) J T x_{n}\right), \\
C_{n+1} & =\left\{v \in C_{n}: \phi\left(v, y_{n}\right) \leq \phi\left(v, x_{n}\right)\right\}, \\
x_{n+1} & =\prod_{C_{n+1}} x_{0},
\end{aligned}
$$

for $n \in \mathbb{N} \cup\{0\}$, where $J$ is the single-valued duality mapping on $E$. Then $\left\{x_{n}\right\}$ converges strongly to $\Pi_{F(T)} x_{0}$. 
Corollary 3.8. Let $E$ be a uniformly convex and uniformly smooth Banach space and let $C$ be a nonempty bounded closed convex subset of $E$. Let $T: C \rightarrow C$ be a closed relatively nonexpansive mapping from $C$ into itself such that $F(T) \neq \emptyset$. Assume that $\left\{\alpha_{n}\right\}_{n=0}^{\infty}$ is a sequence in $[0,1]$ such that $\limsup _{n \rightarrow \infty} \alpha_{n}<1$ and let a sequence $\left\{x_{n}\right\}$ in $C$ be defined by the following algorithm:

$$
\begin{aligned}
x_{0} & \in C, \quad \text { chosen arbitrarity, } \quad C_{0}=C, \\
y_{n} & =J^{-1}\left(\alpha_{n} J x_{n}+\left(1-\alpha_{n}\right) J T x_{n}\right), \\
C_{n+1} & =\left\{v \in C_{n}: \phi\left(v, y_{n}\right) \leq \phi\left(v, x_{n}\right)\right\}, \\
x_{n+1} & =\prod_{C_{n+1}} x_{0},
\end{aligned}
$$

for $n \in \mathbb{N} \cup\{0\}$, where $J$ is the single-valued duality mapping on $E$. Then $\left\{x_{n}\right\}$ converges strongly to $\Pi_{F(T)} x_{0}$.

Similarly, as in the proof of Theorem 3.1, we obtain the following results.

Theorem 3.9. Let $E$ be a uniformly convex and uniformly smooth Banach space and let $C$ be a nonempty bounded closed convex subset of $E$. Let $\left\{T_{n}\right\}$ be a sequence of hemi-relatively nonexpansive mappings from $C$ into itself such that $\bigcap_{n=0}^{\infty} F\left(T_{n}\right)$ is nonempty. Assume that $\left\{\alpha_{n}\right\}_{n=0}^{\infty}$ and $\left\{\beta_{n}\right\}_{n=0}^{\infty}$ are sequences in $[0,1]$ such that $\limsup _{n \rightarrow \infty} \alpha_{n}<1$ and $\lim _{n \rightarrow \infty} \beta_{n}<1$ and let a sequence $\left\{x_{n}\right\}$ in $C$ be defined by the following algorithm:

$$
\begin{aligned}
x_{0} & \in C, \quad \text { chosen arbitrarity, } \quad C_{0}=C, \\
y_{n} & =J^{-1}\left(\alpha_{n} J x_{n}+\left(1-\alpha_{n}\right) J T_{n} z_{n}\right), \\
z_{n} & =J^{-1}\left(\beta_{n} J x_{n}+\left(1-\beta_{n}\right) J T_{n} x_{n}\right), \\
C_{n} & =\left\{v \in C: \phi\left(v, y_{n}\right) \leq \phi\left(v, x_{n}\right)\right\}, \\
Q_{n} & =\left\{v \in C:\left\langle v-x_{n}, J x_{n}-J x_{0}\right\rangle \geq 0\right\}, \\
x_{n+1} & =\Pi_{C_{n} \cap Q_{n}} x_{0},
\end{aligned}
$$

for $n \in \mathbb{N} \cup\{0\}$, where $J$ is the single-valued duality mapping on E. Suppose that for each bounded subset $B$ of $C$, the ordered pair $\left(\left\{T_{n}\right\}, B\right)$ satisfies either condition AKTT or condition *AKTT. Let $T$ be the mapping from $C$ into itself defined by $T v=\lim _{n \rightarrow \infty} T_{n} v$ for all $v \in C$ and suppose that $T$ is closed and $F(T)=\bigcap_{n=0}^{\infty} F\left(T_{n}\right)$. If $T_{n}$ is uniformly continuous for all $n \in \mathbb{N}$, then $\left\{x_{n}\right\}$ converges strongly to $\Pi_{F(T)} x_{0}$, where $\Pi_{F(T)}$ is the generalized projection from $C$ onto $F(T)$.

Corollary 3.10. Let $E$ be a uniformly convex and uniformly smooth Banach space and let $C$ be a nonempty bounded closed convex subset of $E$. Let $T: C \rightarrow C$ be closed hemi-relatively nonexpansive mappings from $C$ into itself such that $F(T) \neq \emptyset$. Assume that $\left\{\alpha_{n}\right\}_{n=0}^{\infty}$ and $\left\{\beta_{n}\right\}_{n=0}^{\infty}$ are sequences in $[0,1]$ such that $\limsup _{n \rightarrow \infty} \alpha_{n}<1$ and $\limsup _{n \rightarrow \infty} \beta_{n}=1$ and let a sequence $\left\{x_{n}\right\}$ in $C$ be defined 
by the following algorithm:

$$
\begin{aligned}
& x_{0} \in C, \quad \text { chosen arbitrarity, } C_{0}=C, \\
& y_{n}=J^{-1}\left(\alpha_{n} J x_{n}+\left(1-\alpha_{n}\right) J T z_{n}\right), \\
& z_{n}=J^{-1}\left(\beta_{n} J x_{n}+\left(1-\beta_{n}\right) J T x_{n}\right), \\
& C_{n}=\left\{v \in C: \phi\left(v, y_{n}\right) \leq \phi\left(v, x_{n}\right)\right\}, \\
& Q_{n}=\left\{v \in C:\left\langle v-x_{n}, J x_{n}-J x_{0}\right\rangle \geq 0\right\}, \\
& x_{n+1}=\Pi_{C_{n} \cap Q_{n}}\left(x_{0}\right),
\end{aligned}
$$

for $n \in \mathbb{N} \cup\{0\}$, where $J$ is the single-valued duality mapping on E. If $T$ is uniformly continuous, then $\left\{x_{n}\right\}$ converges strongly to $\Pi_{F(T)} x_{0}$.

Theorem 3.11. Let $E$ be a uniformly convex and uniformly smooth Banach space and let $C$ be a nonempty bounded closed convex subset of $E$. Let $\left\{T_{n}\right\}$ be a sequence of relatively nonexpansive mappings from $C$ into itself such that $\bigcap_{n=0}^{\infty} F\left(T_{n}\right)$ is a nonempty. Assume that $\left\{\alpha_{n}\right\}_{n=0}^{\infty}$ is a sequence in $[0,1]$ such that $\limsup _{n \rightarrow \infty} \alpha_{n}<1$ and let a sequence $\left\{x_{n}\right\}$ in $C$ be defined by the following algorithm:

$$
\begin{aligned}
& x_{0} \in C, \quad \text { chosen arbitrarity, } \quad C_{0}=C, \\
& y_{n}=J^{-1}\left(\alpha_{n} J x_{n}+\left(1-\alpha_{n}\right) J T_{n} x_{n}\right), \\
& C_{n}=\left\{v \in C: \phi\left(v, y_{n}\right) \leq \phi\left(v, x_{n}\right)\right\}, \\
& Q_{n}=\left\{v \in C:\left\langle v-x_{n}, J x_{n}-J x_{0}\right\rangle \geq 0\right\}, \\
& x_{n+1}=\prod_{C_{n} \cap Q_{n}} x_{0},
\end{aligned}
$$

for $n \in \mathbb{N} \cup\{0\}$, where $J$ is the single-valued duality mapping on $E$. Suppose that for each bounded subset $B$ of $C$, the ordered pair $\left(\left\{T_{n}\right\}, B\right)$ satisfies either condition AKTT or condition *AKTT. Let $T$ be the mapping from $C$ into itself defined by $T v=\lim _{n \rightarrow \infty} T_{n} v$ for all $v \in C$ and suppose that $T$ is closed and $F(T)=\bigcap_{n=0}^{\infty} F\left(T_{n}\right)$. Then $\left\{x_{n}\right\}$ converges strongly to $\Pi_{F(T)} x_{0}$.

Proof. Putting $\beta_{n}=1$, for all $n \in \mathbb{N} \cup\{0\}$, in Theorem 3.9 we immediately obtain Theorem 3.11.

Corollary 3.12. Let $E$ be a uniformly convex and uniformly smooth Banach space and let $C$ be a nonempty bounded closed convex subset of $E$. Let $T: C \rightarrow C$ be closed hemi-relatively nonexpansive mappings from $C$ into itself such that $F(T) \neq \emptyset$. Assume that $\left\{\alpha_{n}\right\}_{n=0}^{\infty}$ is a sequence in $[0,1]$ such that 
$\limsup _{n \rightarrow \infty} \alpha_{n}<1$ and let a sequence $\left\{x_{n}\right\}$ in $C$ be defined by the following algorithm:

$$
\begin{aligned}
x_{0} & \in C, \quad \text { chosen arbitrarity, } C_{0}=C, \\
y_{n} & =J^{-1}\left(\alpha_{n} J x_{n}+\left(1-\alpha_{n}\right) J T x_{n}\right), \\
C_{n} & =\left\{v \in C: \phi\left(v, y_{n}\right) \leq \phi\left(v, x_{n}\right)\right\}, \\
Q_{n} & =\left\{v \in C:\left\langle v-x_{n}, J x_{n}-J x_{0}\right\rangle \geq 0\right\}, \\
x_{n+1} & =\Pi_{C_{n} \cap Q_{n}} x_{0},
\end{aligned}
$$

for $n \in \mathbb{N} \cup\{0\}$, where $J$ is the single-valued duality mapping on $E$. Then $\left\{x_{n}\right\}$ converges strongly to $\Pi_{F(T)} x_{0}$.

Remark 3.13. Our results extend and improve the corresponding results in the following senses.

(i) Corollary 3.10 improves Theorem 2.1 of Qin and Su [15] from relatively nonexpansive mappings to more general hemi-relatively nonexpansive mappings.

(ii) Theorem 3.11 improves the algorithm in Theorem 3.1 of Nilsakoo and Saejung [19] from the Mann iteration process to modify Ishikawa iteration process and from countable relatively nonexpansive mappings to more general countable hemirelatively nonexpansive mappings; that is, we relax the strong restriction $\widehat{F}(T)=$ $F(T)$. From (i) and (ii), it means that we relax the strongly restriction as $\widehat{F}(T)=F(T)$ from the assumption.

(iii) Corollary 3.12 improves Theorem 3.1 of Matsushita and Takahashi [14] from relatively nonexpansive mappings to more general hemi-relatively nonexpansive mappings in a Banach space.

\section{Halpern Iterative Scheme}

In this section, we prove the strong convergence theorems for finding common fixed points of a countable family of hemi-relatively nonexpansive mappings, which can be viewed as a generalization of the recently result of [15, Theorem 2.2].

Theorem 4.1. Let $E$ be a uniformly convex and uniformly smooth Banach space and let $C$ be a nonempty bounded closed convex subset of $E$. Let $\left\{T_{n}\right\}$ be a sequence of hemi-relatively nonexpansive mappings from $C$ into itself such that $\bigcap_{n=0}^{\infty} F\left(T_{n}\right)$ is nonempty. Assume that $\left\{\alpha_{n}\right\}_{n=0}^{\infty}$ is a sequence in $(0,1)$ such that $\lim _{n \rightarrow \infty} \alpha_{n}=0$ and let a sequence $\left\{x_{n}\right\}$ in $C$ be defined by the following algorithm:

$$
\begin{aligned}
x_{0} & \in C, \quad \text { chosen arbitrarity, } \quad C_{0}=C, \\
y_{n} & =J^{-1}\left(\alpha_{n} J x_{0}+\left(1-\alpha_{n}\right) J T_{n} x_{n}\right), \\
C_{n+1} & =\left\{v \in C_{n}: \phi\left(v, y_{n}\right) \leq \alpha_{n} \phi\left(v, x_{0}\right)+\left(1-\alpha_{n}\right) \phi\left(v, x_{n}\right)\right\}, \\
x_{n+1} & =\prod_{C_{n+1}} x_{0},
\end{aligned}
$$


for $n \in \mathbb{N} \cup\{0\}$, where $J$ is the single-valued duality mapping on $E$. Suppose that for each bounded subset $B$ of $C$, the ordered pair $\left(\left\{T_{n}\right\}, B\right)$ satisfies either condition AKTT or condition *AKTT. Let $T$ be the mapping from $C$ into itself defined by $T v=\lim _{n \rightarrow \infty} T_{n} v$ for all $v \in C$ and suppose that $T$ is closed and $F(T)=\bigcap_{n=0}^{\infty} F\left(T_{n}\right)$. Then $\left\{x_{n}\right\}$ converges strongly to $\Pi_{F(T)} x_{0}$.

Proof. As in the proof of Theorem 3.1, we have that $C_{n+1}$ is closed and convex for each $n \geq 0$. Next, we show that $\bigcap_{n=0}^{\infty} F\left(T_{n}\right) \subset C_{n}$ for all $n \geq 0$. Indeed, let $p \in \bigcap_{n=0}^{\infty} F\left(T_{n}\right)$, we have

$$
\begin{aligned}
\phi\left(p, y_{n}\right) & =\phi\left(p, J^{-1}\left(\alpha_{n} J x_{0}+\left(1-\alpha_{n}\right) J T_{n} x_{n}\right)\right) \\
& =\|p\|^{2}-2\left\langle p, \alpha_{n} J x_{0}+\left(1-\alpha_{n}\right) J T^{n} x_{n}\right\rangle+\left\|\alpha_{n} J \mathrm{x}_{0}+\left(1-\alpha_{n}\right) J T_{n} x_{n}\right\|^{2} \\
& \leq\|p\|^{2}-2 \alpha_{n}\left\langle p, J x_{0}\right\rangle-2\left(1-\alpha_{n}\right)\left\langle p, J T_{n} x_{n}\right\rangle+\alpha_{n}\left\|x_{0}\right\|^{2}+\left(1-\alpha_{n}\right)\left\|T_{n} x_{n}\right\|^{2} \\
& =\alpha_{n}\left(\|p\|^{2}-2\left\langle p, J x_{0}\right\rangle+\left\|x_{0}\right\|^{2}\right)+\left(1-\alpha_{n}\right)\left(\|p\|^{2}-2\left\langle p, J T_{n} x_{n}\right\rangle+\left\|T_{n} x_{n}\right\|^{2}\right) \\
& \leq \alpha_{n} \phi\left(p, x_{0}\right)+\left(1-\alpha_{n}\right) \phi\left(p, T_{n} x_{n}\right) \\
& \leq \alpha_{n} \phi\left(p, x_{0}\right)+\left(1-\alpha_{n}\right) \phi\left(p, x_{n}\right) .
\end{aligned}
$$

This means that, $p \in C_{n+1}$ for all $n \geq 0$. From Theorem 3.1, we obtain $\lim _{n \rightarrow \infty} \phi\left(x_{n+1}, x_{n}\right)=0$ and $\lim _{n \rightarrow \infty} \phi\left(x_{n}, x_{0}\right)$ exists. Since $x_{n+1}=\prod_{C_{n+1}} x_{0}$ and hence $x_{n+1} \in C_{n+1} \subset C_{n}$, we also get

$$
\phi\left(x_{n+1}, y_{n}\right) \leq \alpha_{n} \phi\left(x_{n+1}, x_{0}\right)+\left(1-\alpha_{n}\right) \phi\left(x_{n+1}, x_{n}\right),
$$

for all $n \geq 0$. Since $\lim _{n \rightarrow \infty} \alpha_{n}=0$, thus, $\phi\left(x_{n+1}, y_{n}\right) \rightarrow 0$ as $n \rightarrow \infty$.

By using the same argument as in Theorem 3.1, we obtain that $\left\{x_{n}\right\}$ is a Cauchy sequence, thus $\left\{x_{n}\right\}$ converges strongly to $p$ for some point $p$ in C. By using Lemma 2.3, we also have

$$
\lim _{n \rightarrow \infty}\left\|x_{n+1}-y_{n}\right\|=\lim _{n \rightarrow \infty}\left\|x_{n+1}-x_{n}\right\|=0
$$

Since $J$ is uniformly norm-to-norm continuous on bounded sets, we have

$$
\lim _{n \rightarrow \infty}\left\|J x_{n+1}-J y_{n}\right\|=\lim _{n \rightarrow \infty}\left\|J x_{n+1}-J x_{n}\right\|=0 .
$$

Observe that

$$
\begin{aligned}
\left\|J x_{n+1}-J y_{n}\right\| & =\left\|J x_{n+1}-\left(\alpha_{n} J x_{0}+\left(1-\alpha_{n}\right) J T_{n} x_{n}\right)\right\| \\
& =\left\|\alpha_{n}\left(J x_{n+1}-J x_{0}\right)+\left(1-\alpha_{n}\right)\left(J x_{n+1}\right)-J T_{n} x_{n}\right\| \\
& =\left\|\left(1-\alpha_{n}\right)\left(J x_{n+1}-J T_{n} x_{n}\right)-\alpha_{n}\left(J x_{0}-J x_{n+1}\right)\right\| \\
& \geq\left(1-\alpha_{n}\right)\left\|J x_{n+1}-J T_{n} x_{n}\right\|-\alpha_{n}\left\|J x_{0}-J x_{n+1}\right\|,
\end{aligned}
$$


this gives

$$
\left\|J x_{n+1}-J T_{n} x_{n}\right\| \leq \frac{1}{1-\alpha_{n}}\left(\left\|J x_{n+1}-J y_{n}\right\|+\alpha_{n}\left\|J x_{0}-J x_{n+1}\right\|\right)
$$

By (4.5) and $\lim _{n \rightarrow \infty} \alpha_{n}=0$, we obtain $\lim _{n \rightarrow \infty}\left\|J x_{n+1}-J T_{n} x_{n}\right\|=0$. Since $J^{-1}$ is uniformly norm-to-norm continuous on bounded sets, we have

$$
\lim _{n \rightarrow \infty}\left\|x_{n+1}-T_{n} x_{n}\right\|=0
$$

It follows from (4.4) that $\left\|x_{n}-T_{n} x_{n}\right\| \leq\left\|x_{n}-x_{n+1}\right\|+\left\|x_{n+1}-T_{n} x_{n}\right\| \rightarrow 0$, as $n \rightarrow \infty$, and since $J^{-1}$ is uniformly norm-to-norm continuous on bounded sets, we get $\lim _{n \rightarrow \infty}\left\|J x_{n}-J T_{n} x_{n}\right\|=0$. From the conditions *AKTT, AKTT, Lemmas 2.7 and 2.8, by using the same line as in the proof of Theorem 3.1, the both two cases, we know that

$$
\lim _{n \rightarrow \infty}\left\|x_{n}-T x_{n}\right\|=0
$$

Finally, we prove that $x_{n} \rightarrow p$, where $p=\Pi_{F(T)} x_{0}$. Let $\left\{x_{n_{i}}\right\}$ be a subsequence of $\left\{x_{n}\right\}$ such that $\left\{x_{n_{i}}\right\} \rightarrow q \in C$. Replacing $q^{\prime}=\Pi_{F(T)} x_{0}$, from $x_{n+1}=\Pi_{C_{n+1}} x_{0}$ and $q^{\prime} \in F \subset C_{n+1}$, we have $\phi\left(x_{n+1}, x_{0}\right) \leq \phi\left(q^{\prime}, x_{0}\right)$. On the other hand, from weakly lower semicontinuity of the norm, we have

$$
\begin{aligned}
\phi\left(q, x_{0}\right) & =\|q\|^{2}-2\left\langle q, J x_{0}\right\rangle+\left\|x_{0}\right\|^{2} \\
& \leq \lim _{i \rightarrow \infty} \inf \left(\left\|x_{n_{i}}\right\|^{2}-\left\langle x_{n_{i}}, J x_{0}\right\rangle+\left\|x_{0}\right\|^{2}\right) \\
& \leq \lim _{i \rightarrow \infty} \inf \phi\left(x_{n_{i}}, x_{0}\right) \leq \lim _{i \rightarrow \infty} \sup \phi\left(x_{n_{i}}, x_{0}\right) \\
& \leq \phi\left(q^{\prime}, x_{0}\right) .
\end{aligned}
$$

From the definition of $\Pi_{F(T)} x_{0}$, since $q=\Pi_{F(T)} x_{0}$, we have $\lim _{n \rightarrow \infty} \phi\left(x_{n_{i}}, x_{0}\right)=\phi\left(q, x_{0}\right)$. This implies $\lim _{n \rightarrow \infty}\left\|x_{n_{i}}\right\|=\|q\|$. Using the Kadec-Klee property ([24]) of the space $E$, we obtain that $\left\{x_{n_{i}}\right\}$ converges strongly to $\Pi_{F(T)} x_{0}$. Since $\left\{x_{n_{i}}\right\}$ is an arbitrary weakly convergent sequence of $\left\{x_{n}\right\}$, we can conclude that $\left\{x_{n}\right\}$ convergence strongly to $\Pi_{F(T)} x_{0}$.

Corollary 4.2. Let $E$ be a uniformly convex and uniformly smooth Banach space and let $C$ be a nonempty bounded closed convex subset of $E$. Let $T$ be a closed hemi-relatively nonexpansive mapping from $C$ into itself such that $F(T)$ is nonempty. Assume that $\left\{\alpha_{n}\right\}_{n=0}^{\infty}$ is a sequence in $(0,1)$ such that $\lim _{n \rightarrow \infty} \alpha_{n}=0$ and let a sequence $\left\{x_{n}\right\}$ in $C$ be defined by the following algorithm:

$$
\begin{aligned}
x_{0} & \in C, \quad \text { chosen arbitrarity, } \quad C_{0}=C, \\
y_{n} & =J^{-1}\left(\alpha_{n} J x_{0}+\left(1-\alpha_{n}\right) J T x_{n}\right), \\
C_{n+1} & =\left\{v \in C_{n}: \phi\left(v, y_{n}\right) \leq \alpha_{n} \phi\left(v, x_{0}\right)+\left(1-\alpha_{n}\right) \phi\left(v, x_{n}\right)\right\}, \\
x_{n+1} & =\prod_{C_{n+1}} x_{0},
\end{aligned}
$$


for $n \in \mathbb{N} \cup\{0\}$, where $J$ is the single-valued duality mapping on $E$. Then $\left\{x_{n}\right\}$ converges strongly to $\Pi_{F(T)} x_{0}$.

Proof. By setting $T_{n} \equiv T$ for all $n \in \mathbb{N} \cup\{0\}$, we immediately obtain the result.

Since every relatively nonexpansive mapping is a hemi-relatively nonexpansive mapping, we immediately obtain the following corollaries.

Corollary 4.3. Let $E$ be a uniformly convex and uniformly smooth Banach space and let $C$ be a nonempty bounded closed convex subset of $E$. Let $\left\{T_{n}\right\}$ be a sequence of relatively nonexpansive mappings from $C$ into itself such that $\bigcap_{n=0}^{\infty} F\left(T_{n}\right)$ is nonempty. Assume that $\left\{\alpha_{n}\right\}_{n=0}^{\infty}$ is a sequence in $(0,1)$ such that $\lim _{n \rightarrow \infty} \alpha_{n}=0$ and let a sequence $\left\{x_{n}\right\}$ in $C$ be defined by the following algorithm:

$$
\begin{aligned}
x_{0} & \in C, \quad \text { chosen arbitrarity, } \quad C_{0}=C, \\
y_{n} & =J^{-1}\left(\alpha_{n} J x_{0}+\left(1-\alpha_{n}\right) J T_{n} x_{n}\right), \\
C_{n+1} & =\left\{v \in C_{n}: \phi\left(v, y_{n}\right) \leq \alpha_{n} \phi\left(v, x_{0}\right)+\left(1-\alpha_{n}\right) \phi\left(v, x_{n}\right)\right\}, \\
x_{n+1} & =\Pi_{C_{n+1}} x_{0},
\end{aligned}
$$

for $n \in \mathbb{N} \cup\{0\}$, where $J$ is the single-valued duality mapping on $E$. Suppose that for each bounded subset $B$ of $C$, the ordered pair $\left(\left\{T_{n}\right\}, B\right)$ satisfies either condition AKTT or condition * $A K T T$. Let $T$ be the mapping from $C$ into itself defined by $T v=\lim _{n \rightarrow \infty} T_{n} v$ for all $v \in C$ and suppose that $T$ is closed and $F(T)=\bigcap_{n=0}^{\infty} F\left(T_{n}\right)$. Then $\left\{x_{n}\right\}$ converges strongly to $\Pi_{F(T)} x_{0}$.

Corollary 4.4. Let $E$ be a uniformly convex and uniformly smooth Banach space and let $C$ be a nonempty bounded closed convex subset of $E$. Let $T$ be a closed relatively nonexpansive mapping from $C$ into itself such that $F(T)$ is nonempty. Assume that $\left\{\alpha_{n}\right\}_{n=0}^{\infty}$ is a sequence in $(0,1)$ such that $\lim _{n \rightarrow \infty} \alpha_{n}=0$ and let a sequence $\left\{x_{n}\right\}$ in $C$ be defined by the following algorithm:

$$
\begin{aligned}
x_{0} & \in C, \quad \text { chosen arbitrarity, } \quad C_{0}=C, \\
y_{n} & =J^{-1}\left(\alpha_{n} J x_{0}+\left(1-\alpha_{n}\right) J T x_{n}\right), \\
C_{n+1} & =\left\{v \in C_{n}: \phi\left(v, y_{n}\right) \leq \alpha_{n} \phi\left(v, x_{0}\right)+\left(1-\alpha_{n}\right) \phi\left(v, x_{n}\right)\right\}, \\
x_{n+1} & =\prod_{C_{n+1}} x_{0},
\end{aligned}
$$

for $n \in \mathbb{N} \cup\{0\}$, where $J$ is the single-valued duality mapping on E. Then $\left\{x_{n}\right\}$ converges strongly to $\Pi_{F(T)} x_{0}$.

Similarly, as in the proof of Theorem 4.1, we obtain the following result.

Theorem 4.5. Let E be a uniformly convex and uniformly smooth Banach space and let $C$ be a nonempty bounded closed convex subset of $E$. Let $\left\{T_{n}\right\}$ be a sequence of hemi-relatively nonexpansive mappings from $C$ into itself such that $\bigcap_{n=0}^{\infty} F\left(T_{n}\right)$ is nonempty. Assume that $\left\{\alpha_{n}\right\}_{n=0}^{\infty}$ is a sequence 
in $(0,1)$ such that $\lim _{n \rightarrow \infty} \alpha_{n}=0$ and let a sequence $\left\{x_{n}\right\}$ in $C$ be defined by the following algorithm:

$$
\begin{aligned}
x_{0} \in C, \quad \text { chosen arbitrarity, } \quad C_{0}=C, & \\
y_{n} & =J^{-1}\left(\alpha_{n} J x_{0}+\left(1-\alpha_{n}\right) J T_{n} x_{n}\right), \\
C_{n} & =\left\{v \in C: \phi\left(v, y_{n}\right) \leq \alpha_{n} \phi\left(v, x_{0}\right)+\left(1-\alpha_{n}\right) \phi\left(v, x_{n}\right)\right\}, \\
Q_{n} & =\left\{v \in C:\left\langle v-x_{n}, J x_{n}-J x_{0}\right\rangle \geq 0\right\}, \\
x_{n+1} & =\prod_{C_{n} \cap Q_{n}} x_{0},
\end{aligned}
$$

for $n \in \mathbb{N} \cup\{0\}$, where $J$ is the single-valued duality mapping on $E$. Suppose that for each bounded subset $B$ of $C$, the ordered pair $\left(\left\{T_{n}\right\}, B\right)$ satisfies either condition AKTT or condition *AKTT. Let $T$ be the mapping from $C$ into itself defined by $T v=\lim _{n \rightarrow \infty} T_{n} v$ for all $v \in C$ and suppose that $T$ is closed and $F(T)=\bigcap_{n=0}^{\infty} F\left(T_{n}\right)$. Then $\left\{x_{n}\right\}$ converges strongly to $\Pi_{F(T)} x_{0}$.

If $T_{n}=T$, then Theorem 4.5 reduces to the following corollary.

Corollary 4.6 (see [15, Theorem 2.2]). Let E be a uniformly convex and uniformly smooth Banach space and let $C$ be a nonempty bounded closed convex subset of $E$. Let $T: C \rightarrow C$ be a closed relatively nonexpansive mapping from $C$ into itself such that $F(T) \neq \emptyset$. Assume that $\left\{\alpha_{n}\right\}_{n=0}^{n}$ is a sequence in $(0,1)$ such that $\lim _{n \rightarrow \infty} \alpha_{n}=0$ and let a sequence $\left\{x_{n}\right\}$ in $C$ be defined by the following algorithm:

$$
\begin{aligned}
x_{0} & \in C, \quad \text { chosen arbitrarity, } C_{0}=C, \\
y_{n} & =J^{-1}\left(\alpha_{n} J x_{0}+\left(1-\alpha_{n}\right) J T x_{n}\right), \\
C_{n} & =\left\{v \in C: \phi\left(v, y_{n}\right) \leq \alpha_{n} \phi\left(v, x_{0}\right)+\left(1-\alpha_{n}\right) \phi\left(v, x_{n}\right)\right\}, \\
Q_{n} & =\left\{v \in C:\left\langle v-x_{n}, J x_{n}-J x_{0}\right\rangle \geq 0\right\}, \\
x_{n+1} & =\Pi_{C_{n} \cap Q_{n}} x_{0},
\end{aligned}
$$

for $n \in \mathbb{N} \cup\{0\}$, where $J$ is the single-valued duality mapping on $E$. Then $\left\{x_{n}\right\}$ converges strongly to $\Pi_{F(T)} x_{0}$.

\section{Some Applications to Hilbert Spaces}

It is well known that, in the Hilbert space setting, the concepts of hemi-relatively nonexpansive mappings and quasi-nonexpansive mappings are the equivalent. Thus, the following results can be obtained.

Theorem 5.1. Let $H$ be a Hilbert space and let $C$ be a nonempty bounded closed convex subset of $H$. Let $\left\{T_{n}\right\}$ be a sequence of quasi-nonexpansive mappings from $C$ into itself such that $\bigcap_{n=0}^{\infty} F\left(T_{n}\right)$ is nonempty. Assume that $\left\{\alpha_{n}\right\}_{n=0}^{\infty}$ and $\left\{\beta_{n}\right\}_{n=0}^{\infty}$ are sequences in $[0,1]$ such that $\lim _{\sup } \operatorname{sum}_{n \rightarrow \infty} \alpha_{n}<1$ 
and $\lim _{n \rightarrow \infty} \beta_{n}=1$ and let a sequence $\left\{x_{n}\right\}$ in $C$ be defined by the following algorithm:

$$
\begin{aligned}
x_{0} & \in C, \quad \text { chosen arbitrarity, } \quad C_{0}=C, \\
y_{n} & =\alpha_{n} x_{n}+\left(1-\alpha_{n}\right) T_{n} z_{n}, \\
z_{n} & =\beta_{n} x_{n}+\left(1-\beta_{n}\right) T_{n} x_{n}, \\
C_{n+1} & =\left\{v \in C_{n}:\left\|y_{n}-v\right\| \leq\left\|x_{n}-v\right\|\right\}, \\
x_{n+1} & =P_{C_{n+1}} x_{0},
\end{aligned}
$$

for $n \in \mathbb{N} \cup\{0\}$. Suppose that for each bounded subset $B$ of $C$, the ordered pair $\left(\left\{T_{n}\right\}, B\right)$ satisfies condition AKTT. Let $T$ be the mapping from $C$ into itself defined by $T v=\lim _{n \rightarrow \infty} T_{n} v$ for all $v \in C$ and suppose that $T$ is closed and $F(T)=\bigcap_{n=0}^{\infty} F\left(T_{n}\right)$. If $T_{n}$ is uniformly continuous for all $n \in \mathbb{N}$, then $\left\{x_{n}\right\}$ converges strongly to $P_{F(T)} x_{0}$.

Proof. Since $J$ is an identity operator, we have

$$
\phi(x, y)=\|x-y\|^{2}
$$

for every $x, y \in H$. Therefore

$$
\left\|T_{n} x-p\right\| \leq\|x-p\| \Longleftrightarrow \phi\left(p, T_{n} x\right) \leq \phi(p, x),
$$

for every $x \in C$ and $p \in F\left(T_{n}\right)$. Hence, $T_{n}$ is quasi-nonexpansive if and only if $T_{n}$ is hemirelatively nonexpansive. Then, by Theorem 3.1, we obtain the result.

Theorem 5.2. Let $H$ be a Hilbert space and let $C$ be a nonempty bounded closed convex subset of $H$. Let $\left\{T_{n}\right\}$ be a sequence of quasi-nonexpansive mappings from $C$ into itself such that $\bigcap_{n=0}^{\infty} F\left(T_{n}\right)$ is nonempty. Assume that $\left\{\alpha_{n}\right\}_{n=0}^{\infty}$ is sequence in $[0,1]$ such that $\limsup _{n \rightarrow \infty} \alpha_{n}<1$ and let a sequence $\left\{x_{n}\right\}$ in $C$ be defined by the following algorithm:

$$
\begin{aligned}
x_{0} & \in C, \quad \text { chosen arbitrarity, } \quad C_{0}=C, \\
y_{n} & =\alpha_{n} x_{n}+\left(1-\alpha_{n}\right) T_{n} x_{n}, \\
C_{n+1} & =\left\{v \in C_{n}:\left\|y_{n}-v\right\| \leq\left\|x_{n}-v\right\|\right\}, \\
x_{n+1} & =P_{C_{n+1}} x_{0},
\end{aligned}
$$

for $n \in \mathbb{N} \cup\{0\}$. Suppose that for each bounded subset $B$ of $C$, the ordered pair $\left(\left\{T_{n}\right\}, B\right)$ satisfies condition AKTT. Let $T$ be the mapping from $C$ into itself defined by $T v=\lim _{n \rightarrow \infty} T_{n} v$ for all $v \in C$ and suppose that $T$ is closed and $F(T)=\bigcap_{n=0}^{\infty} F\left(T_{n}\right)$. Then $\left\{x_{n}\right\}$ converges strongly to $P_{F(T)} x_{0}$.

Proof. In Theorem 5.1 setting $\beta_{n}=1$ for all $n \in \mathbb{N} \cup\{0\}$, then (5.1) reduces to (5.4). 
Theorem 5.3. Let $H$ be a Hilbert space and let $C$ be a nonempty bounded closed convex subset of $H$. Let $\left\{T_{n}\right\}$ be a sequence of quasi-nonexpansive mappings from $C$ into itself such that $\bigcap_{n=0}^{\infty} F\left(T_{n}\right)$ is nonempty. Assume that $\left\{\alpha_{n}\right\}_{n=0}^{\infty}$ is a sequence in $[0,1]$ such that $\limsup _{n \rightarrow \infty} \alpha_{n}<1$ and let $a$ sequence $\left\{x_{n}\right\}$ in $C$ be defined by the following algorithm:

$$
\begin{aligned}
x_{0} & \in C, \quad \text { chosen arbitrarity, } \quad C_{0}=C, \\
y_{n} & =\alpha_{n} x_{0}+\left(1-\alpha_{n}\right) T_{n} x_{n}, \\
C_{n+1} & =\left\{v \in C_{n}:\left\|y_{n}-v\right\| \leq \alpha_{n}\left\|x_{0}-v\right\|+\left(1-\alpha_{n}\right)\left\|x_{n}-v\right\|\right\}, \\
x_{n+1} & =P_{C_{n+1}} x_{0},
\end{aligned}
$$

for $n \in \mathbb{N} \cup\{0\}$. Suppose that for each bounded subset $B$ of $C$, the ordered pair $\left(\left\{T_{n}\right\}, B\right)$ satisfies condition AKTT. Let $T$ be the mapping from $C$ into itself defined by $T v=\lim _{n \rightarrow \infty} T_{n} v$ for all $v \in C$ and suppose that $T$ is closed and $F(T)=\bigcap_{n=0}^{\infty} F\left(T_{n}\right)$. Then $\left\{x_{n}\right\}$ converges strongly to $P_{F(T)} x_{0}$.

\section{Acknowledgments}

The authors would like to thank the referees for the valuable suggestions which helped to improve this manuscript. This research is supported by the Centre of Excellence in Mathematics, the Commission on Higher Education, Thailand.

\section{References}

[1] W. R. Mann, "Mean value methods in iteration," Proceedings of the American Mathematical Society, vol. 4, pp. 506-510, 1953.

[2] B. Halpern, "Fixed points of nonexpanding maps," Bulletin of the American Mathematical Society, vol. 73, pp. 957-961, 1967.

[3] F. E. Browder, "Fixed-point theorems for noncompact mappings in Hilbert space," Proceedings of the National Academy of Sciences of the United States of America, vol. 53, pp. 1272-1276, 1965.

[4] S. Ishikawa, "Fixed points by a new iteration method," Proceedings of the American Mathematical Society, vol. 44, pp. 147-150, 1974.

[5] H. H. Bauschke and J. M. Borwein, "On projection algorithms for solving convex feasibility problems," SIAM Review, vol. 38, no. 3, pp. 367-426, 1996.

[6] D. C. Youla, "Mathematical theory of image restoration by the method of convex projections," in Image Recovery: Theory and Application, H. Stark, Ed., pp. 29-77, Academic Press, Orlando, Fla, USA, 1987.

[7] F. Zhang and Y. Su, "Strong convergence of modified implicit iteration processes for common fixed points of nonexpansive mappings," Fixed Point Theory and Applications, vol. 2007, Article ID 48174, 9 pages, 2007.

[8] K. Nakprasit, W. Nilsrakoo, and S. Saejung, "Weak and strong convergence theorems of an implicit iteration process for a countable family of nonexpansive mappings," Fixed Point Theory and Applications, vol. 2008, Article ID 732193, 18 pages, 2008.

[9] Y. J. Cho, S. M. Kang, and X. Qin, "Convergence theorems of fixed points for a finite family of nonexpansive mappings in Banach spaces," Fixed Point Theory and Applications, vol. 2008, Article ID 856145, 7 pages, 2008.

[10] K. Aoyama, Y. Kimura, W. Takahashi, and M. Toyoda, “Approximation of common fixed points of a countable family of nonexpansive mappings in a Banach space," Nonlinear Analysis: Theory, Methods E Applications, vol. 67, no. 2, pp. 2350-2360, 2007.

[11] W. Takahashi, Y. Takeuchi, and R. Kubota, "Strong convergence theorems by hybrid methods for families of nonexpansive mappings in Hilbert spaces," Journal of Mathematical Analysis and Applications, vol. 341, no. 1, pp. 276-286, 2008. 
[12] Y. Su, D. Wang, and M. Shang, "Strong convergence of monotone hybrid algorithm for hemi-relatively nonexpansive mappings," Fixed Point Theory and Applications, vol. 2008, Article ID 284613, 8 pages, 2008.

[13] D. Butnariu, S. Reich, and A. J. Zaslavski, "Asymptotic behavior of relatively nonexpansive operators in Banach spaces," Journal of Mathematical Analysis and Applications, vol. 7, no. 2, pp. 151-174, 2001.

[14] S. Matsushita and W. Takahashi, "A strong convergence theorem for relatively nonexpansive mappings in a Banach space," Journal of Approximation Theory, vol. 134, no. 2, pp. 257-266, 2005.

[15] X. Qin and Y. Su, "Strong convergence theorems for relatively nonexpansive mappings in a Banach space," Nonlinear Analysis: Theory, Methods E Applications, vol. 67, no. 6, pp. 1958-1965, 2007.

[16] W. Takahashi and K. Zembayashi, "Strong convergence theorem by a new hybrid method for equilibrium problems and relatively nonexpansive mappings," Fixed Point Theory and Applications, vol. 2008, Article ID 528476, 11 pages, 2008.

[17] S. Matsushita and W. Takahashi, "Weakly and strong convergence theorems for relatively nonexpansive mappings in a Banach space," Fixed Point Theory and Applications, vol. 2004, no. 1, pp. 37-47, 2004.

[18] F. Kohsaka and W. Takahashi, "Block iterative methods for a finite family of relatively nonexpansive mappings in Banach spaces," Fixed Point Theory and Applications, vol. 2007, Article ID 21972, 18 pages, 2007.

[19] W. Nilsrakoo and S. Saejung, "Strong convergence to common fixed points of countable relatively quasi-nonexpansive mappings," Fixed Point Theory and Applications, vol. 2008, Article ID 312454, 19 pages, 2008.

[20] I. Cioranescu, Geometry of Banach Spaces, Duality Mappings and Nonlinear Problems, vol. 62 of Mathematics and Its Applications, Kluwer Academic Publishers, Dordrecht, The Netherlands, 1990.

[21] W. Takahashi, Nonlinear Functional Analysis: Fixed Point Theory and Its Applications, Yokohama Publishers, Yokohama, Japan, 2000.

[22] Ya. I. Alber, "Metric and generalized projection operators in Banach spaces: properties and applications," in Theory and Applications of Nonlinear Operators of Accretive and Monotone Type, A. G. Kartsatos, Ed., vol. 178, pp. 15-50, Marcel Dekker, New York, NY, USA, 1996.

[23] S. Kamimura and W. Takahashi, "Strong convergence of a proximal-type algorithm in a Banach space," SIAM Journal on Optimization, vol. 13, no. 3, pp. 938-945, 2002.

[24] K. Goebel and W. A. Kirk, Topics in Metric Fixed Point Theory, vol. 28 of Cambridge Studies in Advanced Mathematics, Cambridge University Press, Cambridge, UK, 1990. 